\title{
OPENING THE CONVERSATION: HOW ONTARIO PUBLIC LIBRARY WEBSITES
} FRAME DISABILITY (paper)

\begin{abstract}
Résumé:
Public library websites are an early point of contact for the community. These sites are the library's voice when queried by current and potential patrons about services and resources. For those with disabilities, this conversation may include questions around accessibility. This research investigates Ontario public library websites for accessibility information to answer the question, 'How is disability defined by Ontario public libraries?.' Fifteen Ontario public library websites were analyzed through a critical disability framework. Findings indicate a broader framing of accessibility than in previous research using more of a social model, with some instances of disability framed as a binary.
\end{abstract}

\section{Introduction}

Public library websites are often an early point of contact for the community. Acting as the first response to potential new patrons' questions, websites address such overview information as "Where is the library?", "When is it open?", "Does the library have the item I'm looking for?." For persons with disabilities, this initial conversation may also include questions such as "what accessible resources are available?" "Can I access the washroom with my wheelchair?." How these questions are addressed, if they are addressed, provides an initial impression about how the library defines and approaches accessibility.

Being clear about accessible services, resources, and facilities helps show how the library is (or is not) accessible. Having list of accessible services, however, does not necessarily create an accessible environment. There are attitudinal aspects to accessibility, which can override an environment that is otherwise accessible. In brief, attitudinal barriers include how one perceives disability and are displayed when one is uncertain or uncomfortable around folks with disabilities. The framing of accessibility information on a website can potentially indicate how the library has tackled the attitudinal aspects of accessibility. Positive framing provides reassurance to disabled community members ${ }^{\mathrm{i}}$ that the library supports their development as readers, community members, and citizens.

For Ontario libraries, some guidance to providing accessible service are available. As early as 1997, the Canadian Library Association provided guidelines on providing services for persons with disabilities. The newly formed Canadian Federation of Library Associations (CFLA) published guidelines in 2016. Lastly, the Accessibility for Ontarians with Disabilities Act (AODA), in place since 2005, has rolled out accessibility considerations across employment, information and communication technologies, the built environment, customer service, and transportation areas.

This research builds off of and expands previous research from the author which examined 
Ontario public libraries and their adoption of accessibility policies and development of strategies (redacted for review, 2011). The previous research was completed in 2010, just shortly after the first AODA guideline (customer service) went into effect.

\section{Literature}

Research on the topics of library websites and accessibility generally centres on whether the website is accessible for persons with disabilities. Testing is generally done to determine if the website is friendly to those who use screen-readers, those with mobility issues, and those with colour blindness (Maatta Smith, 2014; Hill, 2013; Oud, 2012; Brobst, 2009;). Beyond this comes more recent analysis of websites from the perspective of accessibility of older patrons (Charbonneau, 2014).

Language use and framing of topics on websites have also been of interest to LIS researchers. Websites have been analyzed for their representation of diversity (Mehra \& Davis, 2015), for their information on entrepreneurship (Faulkner, 2018), for their information about early literacy initiatives (Prendergast, 2013), and for the amount and type of information about children's programming (Kanazawa \& Maruyama, 2008), among others.

Two other studies help provide a rationale and shape for the research proposed here. Fauchelle (2017) examined jargon, prohibitive and welcoming language, and multi-lingual information on library websites, handouts, and signage. Fauchelle found that while some libraries used language in a way that accurately reflected their community demographics, all of the libraries under study could benefit from changes made to the language used on their websites. Gabel, Reid, Pearson, Ruiz, and Hume-Dawson (2016) performed a critical discourse analysis of California State University Websites. Their research focused on broader level accessibility issues such as how easy was it to find information on disability and accessibility on the websites and how many pages down into the website it was necessary to travel to find that information. As well, their research analyzed how disability was framed by the websites through the language used to describe services and the co-location of information included in the same area as information on accessible services.

The gap in the literature exists between these two areas. There has been no research looking at the concepts of accessibility and disability and how they are framed on public library websites.

\section{Research Questions}

This paper examines the following research question: How is disability defined by Ontario public libraries? Of focus here is not an analysis of the accessibility of Ontario public library websites, but an analysis of how the websites frame disability and accessibility.

The research question is broken down into three avenues:

1. How prominent is accessibility information?

2. What information on accessibility is available?

3. What language is used to discuss accessible services and in what context is it discussed?

\section{Methodology}


This research uses a critical disability lens where a social model of disability is used. The social model defines disability as a product of systemic and attitudinal barriers in the environment rather than, for example, the older medical model of disability where disability resided solely within an individual deemed lacking in some capacity.

A stratified sample of public libraries was chosen from the 2017 Ontario Public Library Statistics. Five random libraries each were chosen from those serving populations of 30-50,000, $50-100,000$, and 100-250,000. These libraries represent the middle ground libraries. The smallest libraries were excluded because they have far fewer resources. Alternately, the largest libraries were excluded because of the larger number of resources at their disposal.

Each library's website was examined for information on accessibility. Conveniently, this information is often located on one page, but searches were done on each site to make sure no information was missing.

The websites were analyzed from three different angles. First, from a navigation perspective the distance from the home page and ease of navigation to the information was evaluated. Second, the various information items on the pages were coded. Codes included services, hardware, resources, and built environment among others. Third, language and framing were evaluated by analyzing the terminology used around accessibility, the co-location of accessibility information to other information on the site, and the overall location of accessibility information.

\section{Findings}

Preliminary findings indicate much improvement since the 2010 research. All libraries had a page on accessibility. Most, as in 2010 , focus on noting their accessible workstations, services, and other resources. Some libraries, however, were also indicating the accessibility of their library's built environment by noting washroom accessibility, the presence of a wheelchair for use while in the library, accessible parking, curb cuts, etc. This information about the built environment opens the conversation on accessibility in a fundamental way, showing these libraries are not just focused on traditional library resources but overall access for their community.

Emphasis on the websites is still largely on reading materials, not surprising, but the approach has been broadened to print disabilities rather than a focus on visual disabilities. Absent were any links or information about other accessible services such as sensory storytimes, though such programming might be present in the library.

Additional improvements were noted in the location of information on accessibility. In the previous research, more than a few libraries had information on accessibility located under the policies section of the website. Libraries now more uniformly have accessibility information under 'about us' 'using the library' or 'services' section. Each of these three sections is a logical place for this information and one in which a patron would look. A deeper discussion on the pros and cons of locating the information in each section is beyond this proposal. Having said that, there are still instances of labelling accessibility as a 'special' service, which can be othering to patrons. Designating a particular use as 'special' presents disability as a binary where one is 
either 'special' or 'normal' which is problematic (see: Tyjewski, 2006 for a broader justification for not categorizing disability as a binary).

Co-located information provides additional insight into the framing of accessibility. As an example, consider the difference between a page that starts with a listing for 'accessibility' and then outlines 'computer services,' 'local history' and 'readers' advisory' and a page that nestles 'accessibility' between sections on 'employment \& volunteer opportunities' and 'publications.'

\section{Connection to conference theme}

Library websites exist as a contemporary mode of communication. They outline, through what they state and what they omit, who is welcome in the space. Not seeing oneself acknowledged or represented well can create the perception that 'this space is not for me.' What public libraries say about disability and accessibility matters and potentially affects all future interactions.

\section{Reference List:}

Brobst, J. (2009). Evaluating the accessibility of Florida's public library home pages. Libri: International Journal of Libraries \& Information Services, 59(2), 88-103.

Charbonneau, D. H. (2014). Public library websites and adherence to senior-friendly guidelines. Public Library Quarterly, 33(2), 121-130.

Fauchelle, M. A. (2017). Libraries of Babel: exploring library language and its suitability for the community. Library Review, 66(8/9), 612-627.

Faulkner, A. E. (2018). Entrepreneurship resources in US public libraries: website analysis. Reference Services Review, 46(1), 69-90.

Gabriel, S.L., Reid, D, Pearson, H., Ruiz, L., \& Hume-Dawson, R. (2016). Disability and diversity on CSU websites: A critical discourse study. Journal of Diversity in Higher Education 9(1), 64-80.

Hill, H. (2013). Disability and accessibility in the library and information science literature: a content analysis. Library and Information Science Research 35(2), 137-142.

Redacted for blind review (2011).

Kanazawa, M., \& Maruyama, Y. (2008). An evaluation of public library websites: Describing children's services in Japan. Public Library Quarterly, 27(4), 291-310.

Maatta Smith, S. L. . (2014). Web accessibility assessment of urban public library websites. Public Library Quarterly, 33(3), 187-204.

Mehra, B., \& Davis, R. (2015). A strategic diversity manifesto for public libraries in the $21 \mathrm{st}$ century. New Library World, 116(1/2), 15-36.

Oud, J. (2012). How well do Ontario library web sites meet new accessibility requirements? Partnership: The Canadian Journal of Library \& Information Practice \& Research, 7(1), $1-17$.

Prendergast, T. (2013). Growing readers: A Critical analysis of early literacy content for parents on Canadian public library websites. Journal of Library Administration, 53(4), 234-254.

Tyjewski, C. (2006). Ghosts in the machine: Civil rights laws and the hybrid "invisible other," In Dianne Pothier \& Richard Devlin (Eds.), Critical Disability Theory: Essays in Philosophy ,Politics, and Law (106-125). Vancouver: UBC Press. 
'Person first language (persons with disabilities) and variations of 'disabled persons' are purposely used interchangeably here as preferred phrasing is dependent on the person. As well, the former is more common in North America while the latter is more used in the UK. 